\title{
Dermatology
}

\section{Clinical Features and Treatment Outcomes of Vitiligo from the Patients' Perspective: Results of a National Survey in Germany}

\author{
Marc A. Radtke Ines Schäfer Angelika I. Gajur Matthias Augustin \\ Institute for Health Services Research in Dermatology, University Clinics Hamburg-Eppendorf, Hamburg, Germany
}

\section{Key Words}

Vitiligo $\cdot$ Patient satisfaction $\cdot$ Quality of life $\cdot$ Patient benefit index

\begin{abstract}
Background: Vitiligo causes substantial disease burden and patient needs still remain underestimated. Objective: To assess the clinical features, treatment outcomes and satisfaction in patients with vitiligo. Methods: A nationwide, crosssectional German postal survey was conducted. Clinical features and treatment outcomes of vitiligo (affected body surface, comorbidities, treatments applied, patient benefit index [PBI]) were evaluated using a standardized patient questionnaire. Results: 1,023 patients $(71.4 \%$ women, mean age 44.4 years) completed the questionnaire. The average onset of disease was at 24.1 years, and the mean disease duration was 20.3 years. The mean number of body sites affected was 6.9, and the mean affected body surface area was $14.9 \%$. On average, 3.7 therapies had been applied previously, with a total PBI of $1.03 \pm 1.12$. Only $38.7 \%$ experienced a $\mathrm{PBI}>1$, which indicates a minimal patient benefit. Conclusions: Most therapeutic options are considered to be of low patient benefit. There is a need for more beneficial treatments and improved care in patients with vitiligo.
\end{abstract}

Copyright ๑ 2010 S. Karger AG, Basel

\section{Introduction}

As an acquired pigmentation disorder, vitiligo is among the important chronic skin diseases, with a worldwide prevalence of $1-2 \%$ [1]. Manifestation can occur at any age [2]. However, in half of the patients the disease manifests itself before age of 20 [3]. The cause of this condition still remains uncertain. Hypotheses concerning the pathogenesis assume an autoimmune process and often attribute responsibility for the onset of the disease to genetic and realization factors, among others [4-8]. With regard to the clinical manifestation, a current classification differentiates localized vitiligo (focal or segmental) from generalized forms (acrofacial and vulgaris) [9]. The distribution patterns and course of vitiligo vary greatly.

Even though subjective physical complaints are usually absent, experience of the disease is characterized for many patients by feelings of fear and shame which can lead to a decrease in self-confidence and self-esteem, accompanied by difficulties in socialization and personality development [10-13]. Numerous studies have confirmed a substantial negative effect on patients' quality of life and make clear that quality of life decreases with the duration of the disease and number of visits to the doctor [14-16]. Further stress arises from the fact that the disease is not adequately perceived by many doctors [16].

\section{KARGER}

Fax +4161306 1234 E-Mail karger@karger.ch www.karger.com
Dr. med. Marc Alexander Radtke

Institute for Health Services Research in Dermatology

University Clinics Hamburg-Eppendorf

Martinistrasse 52, DE-20246 Hamburg (Germany)

Tel. +49 4074105 5428, Fax +49 4074105 5348,E-Mail m.radtke@uke.de 
Various therapies are available, depending on the localization and extent of lesions, but therapeutic success is in most cases less than satisfactory and evidence is poor $[9,17-19]$. Moreover, there is no rational approach to investigate how patients rate their therapies. The recording of patient-defined therapy goals and patient satisfaction with treatment is already an important component in the assessment of drugs and medicinal products in many countries [20]. In some countries, allocation decisions and cost reimbursement are mostly based on the therapeutic benefit from the patients' perspective [21-23]. These parameters are not only very important in assessing therapeutic success, but even more in the discussion of health-political and health-economic questions in light of the dwindling financial resources in the health care system and the allocation of health services currently observed internationally.

The objective of the present study was to record the clinical spectrum of vitiligo and to investigate patient satisfaction with respect to therapy applied. For this, a questionnaire study was performed on 1,023 vitiligo patients throughout Germany.

\section{Patients and Methods}

\section{Study Design}

A nationwide cross-sectional postal survey on patients with vitiligo was performed using standardized questionnaires.

\section{Patients}

The questionnaires were sent in 2006 and 2007 to 3,319 patient addresses obtained from 2 German vitiligo patient organizations, the 'Vitiligo Verein e.V.' ( $\mathrm{n}=1,969$ sets) and the 'Vitiligo Bund e.V.' ( $n=1,350$ sets). These sets include all registered patients of these organizations. Membership is voluntary and obtained by simple application. There are no data available regarding clinical features of patients in these organizations compared to other patients. Provided an assumed prevalence of $1.0 \%$, about 800,000 patients suffer from vitiligo in Germany. Hence about $0.4 \%$ of patients with vitiligo are members of the patient organizations. Participation of a minimum of 1,000 patients was planned for a valid analysis. The patients were enrolled in the study after being instructed and granting written informed consent. A vote by the Ethics Commission of the State Medical Council Hamburg was obtained prior to the start of the study.

\section{Questionnaire}

Sociodemographic and clinical data were recorded in the first section of the questionnaire. In addition, the patients made graphic sketches of the affected skin areas using a validated, gridlined body schema [24] which contains 1,044 boxes (quadrates of equal size) to be counted. To date, therapies had been listed in a standardized table and their success rated on a 4-step scale. The second section of the questionnaire consisted of questions about therapy goals in vitiligo: patient needs questionnaire (PNQ) and patient benefit questionnaire (PBQ). These questionnaires covered the importance of the 24 therapy goals to calculate the patient benefit index (PBI) [23]. The underlying principle of the PBI is a pre/post recording. Using a 5-step scale, each patient defines how important each of the listed 24 therapy goals is to him, and after completion of therapy rates the extent to which concrete treatment had contributed to goal attainment, again using a 5 -step scale. These assessments can also be performed in a crosssectional study which refers to the last or recent treatment applied. The kind of treatment was asked by an open question. A total benefit score was calculated over all items as a global measure in which the extent of goal attainment is weighted based on the importance in each case (PBI range $0-4)$. The formula is as follows:

$$
P B I=\sum_{i=1}^{k} \frac{P N Q_{i}}{\sum_{i=1}^{k} P N Q_{i}} P B Q_{i}
$$

The PBI has been found valid (high discriminant and convergent validity, $\mathrm{p}<0.001$ ) and reliable (good item discrimination, Cronbach's alpha $>0.94)$ [23].

\section{Statistical Analysis}

Absolute and percent frequencies were calculated for all data. For constant variables such as age, means and median values were calculated for the position as well as standard deviation and range for the scattering. The $\chi^{2}$ test (Fisher's exact test) was used to analyze the relationship between two categorical or qualitative variables. The test of significance was two-sided and was 5\% ( $\mathrm{p} \leq$ 0.05 ), for high significance $0.1 \%$ ( $p \leq 0.001$ ). Single-factor variance analysis was performed using ANOVA. Correlation analyses were performed with Spearman's rank test. The statistical assessment was made with SPSS Version 12.0.

\section{Results}

\section{Sociodemographic Data}

Of the 3,319 questionnaires sent to patients, 1,075 were returned of which 1,023 were used in the analysis. $71.5 \%$ $(\mathrm{n}=594)$ of the patients were women. Mean patient age was $44.4 \pm 14.2$ years (median: 44.0 ), i.e. $45.0 \pm 13.5$ years (median: 44.0) in women and $42.9 \pm 14.2$ years (median: 44.0) in men. The proportion of children aged $<10$ years was $1.6 \%$ (fig. 1$) .13 .2 \%(n=130)$ of the patients were younger than 30 years, $71.8 \%(n=709)$ of the patients were between 30 and 59 years old and 15.0\% ( $\mathrm{n}=$ 148) were between 60 and 89 years old. The mean age at disease manifestation was $24.1 \pm 14.7$ years (median: 21.0), i.e. $24.8 \pm 15.0$ years in men (median: 20.0 ) and $22.1 \pm 14.2$ years in women (median: 24.8 ) (fig. 2). Thus, the average patient had already suffered from vitiligo for $20.3 \pm 12.4$ years (median: 19.0). 


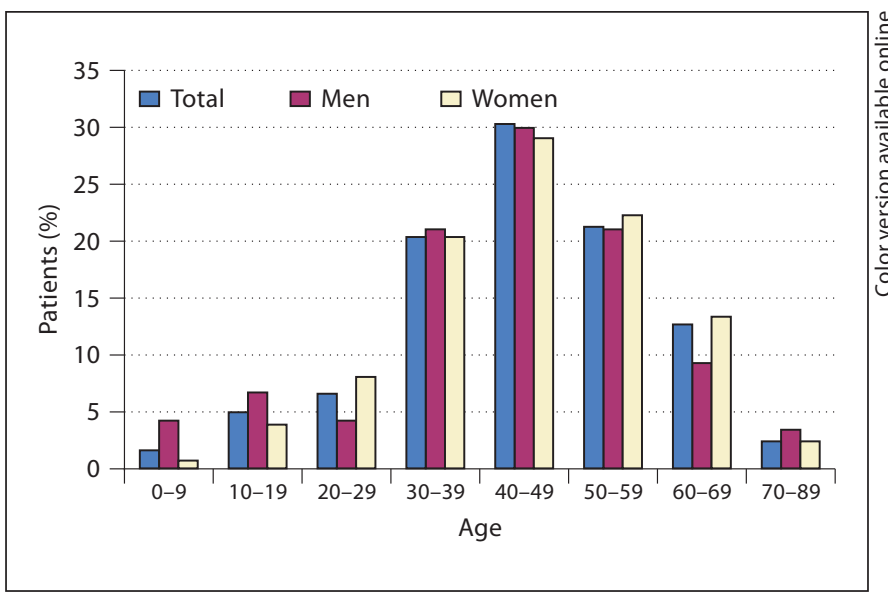

Fig. 1. Age of the patients on examination $(\mathrm{n}=1,012)$.

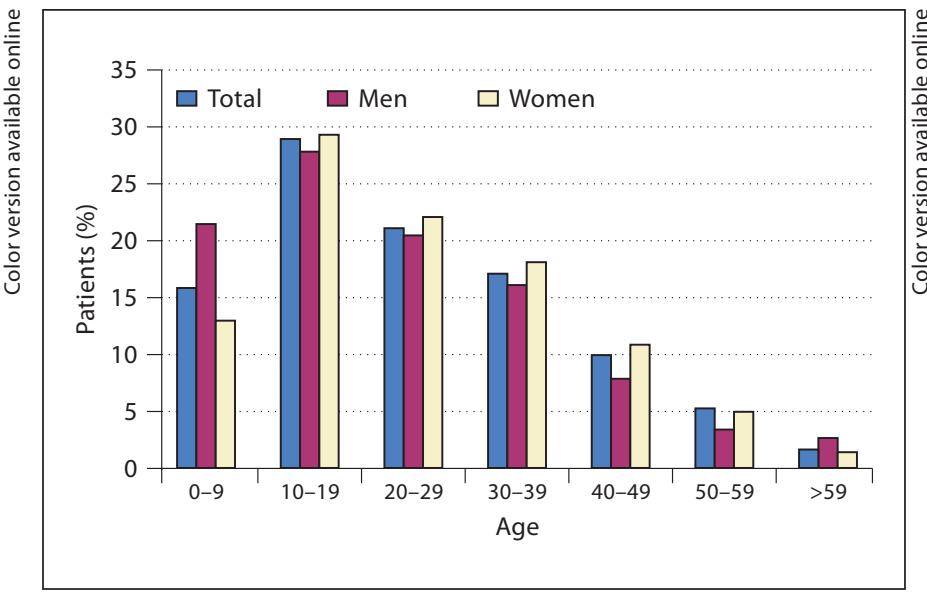

Fig. 2. Age of the patients at first diagnosis $(\mathrm{n}=1,012)$.

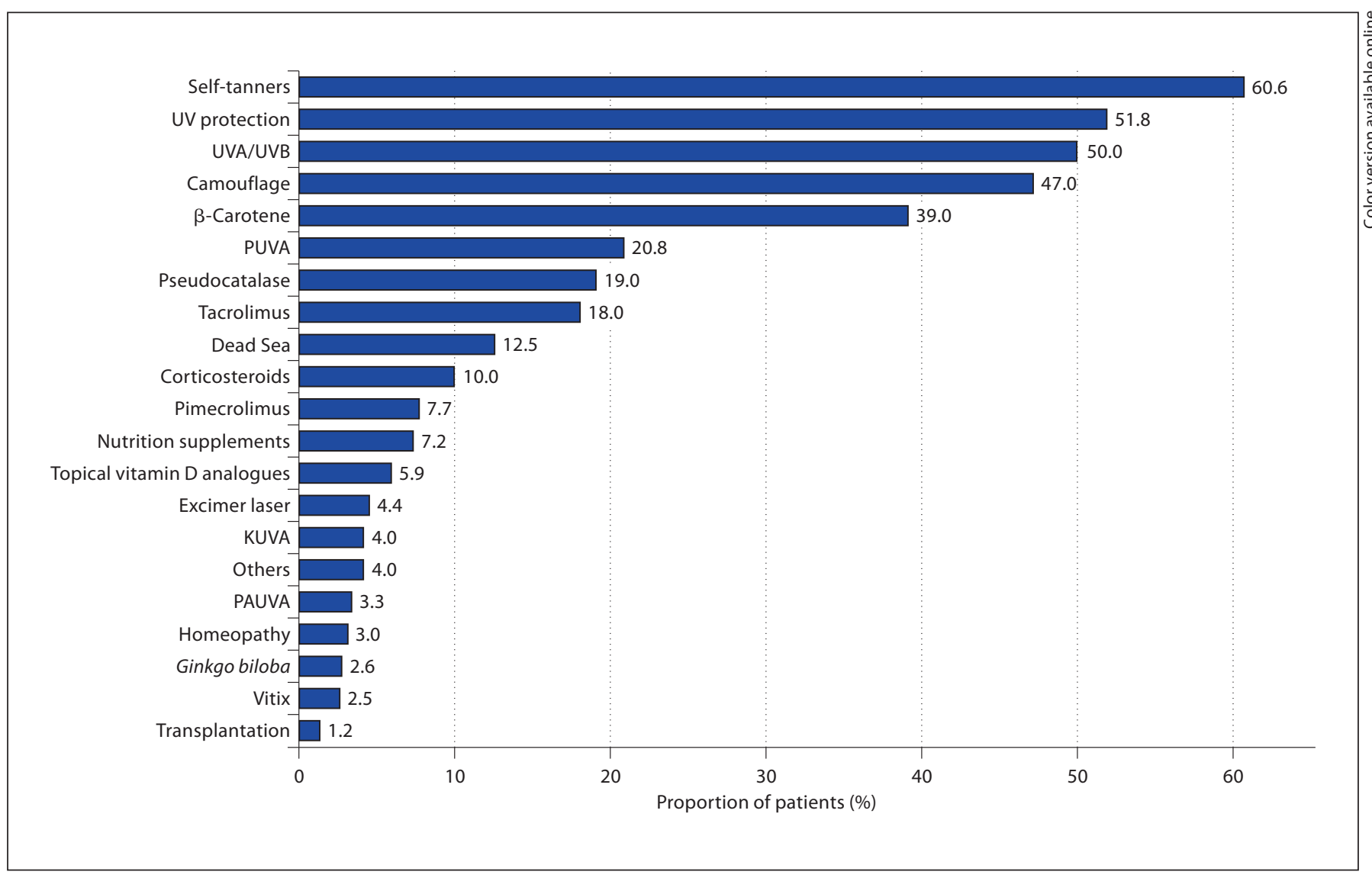

Fig. 3. Proportion of patients $(n=1,012)$ in each therapy applied to date (multiple responses possible). 
Table 1. Frequency of therapies ever used in the two genders (men $n=237$, women $n=594$ ) and their subjectively rated benefits (moderate to good in \%) (multiple responses possible)

\begin{tabular}{|c|c|c|c|c|c|c|c|}
\hline & \multicolumn{4}{|c|}{ Application in } & \multicolumn{2}{|c|}{ Beneficial for } & \multirow{2}{*}{$\begin{array}{l}\mathrm{p}^{\mathrm{a}} \text { (difference } \\
\text { in benefit } \\
\text { men/women) }\end{array}$} \\
\hline & men, $\mathrm{n}$ & men, $\%$ & women, $\mathrm{n}$ & women, \% & men, \% & women, \% & \\
\hline \multicolumn{8}{|l|}{ Cosmetic concealers } \\
\hline Camouflage & 73 & 30.8 & 310 & 52.3 & 47.9 & 57.4 & 0.152 \\
\hline Self-tanner & 105 & 44.3 & 399 & 67.3 & 35.2 & 51.4 & 0.004 \\
\hline UV protection & 88 & 37.1 & 349 & 57.5 & 40.9 & 50.0 & 0.151 \\
\hline \multicolumn{8}{|l|}{ UV treatments } \\
\hline KUVA (khellin + UVA) & 8 & 3.4 & 21 & 3.5 & 12.5 & 23.8 & 0.647 \\
\hline PUVA & 45 & 19.0 & 130 & 21.9 & 17.8 & 15.4 & 0.814 \\
\hline PAUVA (phenylalanine + UVA) & 6 & 2.5 & 15 & 2.5 & 16.7 & 13.3 & 1.000 \\
\hline \multicolumn{8}{|l|}{ Topical prescription } \\
\hline Tacrolimus & 48 & 20.3 & 110 & 18.5 & 39.6 & 21.8 & 0.032 \\
\hline Corticosteroids & 22 & 9.3 & 60 & 10.1 & 31.8 & 20.0 & 0.375 \\
\hline Pimecrolimus & 20 & 8.4 & 42 & 7.1 & 20.0 & 9.5 & 0.418 \\
\hline Vitamin $\mathrm{D}_{3}$ topicals & 12 & 5.1 & 35 & 5.9 & 25.0 & 5.7 & 0.097 \\
\hline \multicolumn{8}{|l|}{ Topical nonprescription } \\
\hline Pseudocatalase & 31 & 13.1 & 125 & 21.1 & 54.8 & 41.6 & 0.227 \\
\hline Vitix $^{\mathrm{b}}$ & 5 & 2.1 & 15 & 2.6 & 20.0 & 6.7 & 0.448 \\
\hline \multicolumn{8}{|l|}{ Surgical treatment } \\
\hline Transplantation & 1 & 0.4 & 7 & 1.2 & 0.0 & 42.9 & 1.000 \\
\hline \multicolumn{8}{|l|}{ Others } \\
\hline Dead Sea & 18 & 7.6 & 80 & 13.5 & 66.7 & 68.8 & 1.000 \\
\hline Nutrient supplement & 13 & 5.8 & 51 & 8.6 & 57.1 & 39.2 & 0.332 \\
\hline Ginkgo biloba & 3 & 1.2 & 16 & 2.7 & 66.7 & 25.0 & 0.222 \\
\hline Excimer laser & 11 & 4.6 & 26 & 4.4 & 9.1 & 19.2 & 0.646 \\
\hline Homeopathy & 5 & 2.1 & 15 & 2.6 & 20.0 & 13.3 & 1.000 \\
\hline$\beta$-Carotene & 75 & 31.6 & 242 & 40.7 & 10.7 & 12.4 & 0.839 \\
\hline Other & 7 & 3.0 & 28 & 4.7 & 57.1 & 25.7 & 0.172 \\
\hline
\end{tabular}

${ }^{\mathrm{a}} \chi^{2}$ test, Fisher's exact test, two-tailed. ${ }^{\mathrm{b}} \mathrm{Gel}$ containing herbal extract with catalase and superoxide dismutase.

\section{Clinical Features}

The mean number of affected body sites was 6.9 (median: 7.0; SD: 2.0). The mean body surface area (BSA) affected was $14.9 \%$, as assessed by the body schema (women: 16.1\%, men: 12.3\%). Body sites which were affected especially often were the hands $(92.1 \%)$, the face $(87.4 \%)$ and the genitals (86.0\%); the lowest rates were found for the neck $(64.7 \%)$ and head $(36.2 \%)$. With respect to comorbidities, $25.7 \%$ of men and $34.5 \%$ of women reported suffering from allergies. Autoimmune diseases were reported by $8.0 \%$ (men) and 29.8\% (women), cardiovascular diseases by $11.4 \%$ (men) and $8.4 \%$ (women).

\section{Use of Therapies and Patient Satisfaction}

The patients had undergone a mean of $3.7 \pm 2.4$ therapies prior to this study (women: 4.0; men: 2.9). Only
$8.3 \%$ of the patients had received no prior therapy. Selftanning preparations were used most frequently (60.6\%), followed by UV protection (51.8\%), UVA/UVB light treatments (50.0\%) and camouflage (47.0\%) (fig. 3). Overall, $75.7 \%$ of those questioned $(82.0 \%$ of the women, $62.4 \%$ of the men) reported having performed one of the cosmetic therapies. Women used markedly more cosmetics, UVA/UVB, Dead Sea therapy (which includes travelling to the Dead Sea), pseudocatalase and natural medicines than men (table 1). On the other hand, men only used slightly more topical therapies like tacrolimus and pimecrolimus than women.

Regarding the patients' subjective assessment of treatment benefit, both genders rated Dead Sea therapy highest, followed by camouflage, self-tanners and UV protection in women and Gingko biloba, nutrient supplement and pseudocatalase in men. Among the topical drugs, ta- 
crolimus was rated higher than corticosteroids, pimecrolimus and vitamin D analogues.

\section{Patient Benefit Assessment}

The PBI was calculated in each patient for the last or recent therapy applied. With a total index of $1.03 \pm 1.12$, the mean PBI was strikingly low (scale from $0=$ no benefit to 4 = maximum benefit). Although the PBI was slightly higher among men, the difference between the genders was not significant. Only $38.7 \%$ experienced a $\mathrm{PBI}>1$, indicating at least a minimum patient benefit. Classification of the PBI by age group and by duration of disease showed no significant differences. Furthermore, there were no statistically significant differences between patients with low and high BSA involved, for example, patients with a BSA $<5 \%$ had a mean PBI of $1.17 \pm 1.22$ and patients with a BSA $>10 \%$ had a mean PBI of $0.97 \pm$ $1.11(\mathrm{p}>0.05)$.

Assessment by the individual therapies showed that the Dead Sea therapy, either alone or in combination with pseudocatalase and possibly with UV treatment, was most likely to attain the patients' therapy goals (mean PBI $1.80 \pm 1.14$; interquartile range $0.87-2.85 ; \mathrm{n}=26)(\mathrm{ta}-$ ble 2). In contrast to the monotherapy rating of cortisone (PBI $0.3 \pm 0.6$ ), the combination of cortisone with UV treatment and/or calcineurin inhibitors showed higher values $(1.6 \pm 1.1)$. Moreover, cosmetic procedures received relatively good ratings. According to the index list, transplantation, $\beta$-carotene, cortisone, light protection alone and G. biloba were rated as 'not very successful at all'. Vitamin $\mathrm{D}_{3}$ had a mean PBI of 1.59 and thus reflected a therapeutic benefit, but it was also in the lower range. A maximum PBI value of 4.0 was only reached in individual cases using Dead Sea, camouflage treatment, the combination of all cosmetic agents, narrow-band UVB light treatment, pseudocatalase therapy and UV treatment.

\section{Discussion}

The objective of this study was to assess the clinical and therapeutic features of vitiligo in a large, nationwide sample in Germany. Satisfaction with treatment and the patients' benefit perception of various therapy options were elucidated based on previous therapeutic experience. The clinical features of vitiligo agree largely with articles published previously. However, this study questioned for the first time a large patient cohort of more than 1,000 patients.
Table 2. Last or recent therapies applied and their PBI (scale from 0 to 4$)(\mathrm{n}=680)$

\begin{tabular}{|c|c|c|c|c|c|}
\hline Therapies & $\mathrm{n}$ & Mean & $\mathrm{SD}$ & Min & Max \\
\hline Dead Sea therapy & 26 & 1.8 & 1.1 & 0.0 & 4.0 \\
\hline $\begin{array}{l}\text { PC-KUS }{ }^{\text {a }} \text {, Dead Sea with/ } \\
\text { without UV }\end{array}$ & 27 & 1.8 & 1.2 & 0.0 & 3.8 \\
\hline $\begin{array}{l}\text { Cortisone with UV or } \\
\text { tacrolimus/pimecrolimus }\end{array}$ & 12 & 1.6 & 1.1 & 0.2 & 2.9 \\
\hline Camouflage & 12 & 1.6 & 1.1 & 0.3 & 4.0 \\
\hline $\begin{array}{l}\text { Camouflage/ } \beta \text {-carotene/ } \\
\text { self-tanner/light protection } \\
\text { in whatever combinations }\end{array}$ & 24 & 1.3 & 1.2 & 0.0 & 4.0 \\
\hline Narrow-band UVB & 39 & 1.3 & 1.2 & 0.0 & 4.0 \\
\hline PAUVA/B & 6 & 1.3 & 1.9 & 0.0 & 3.8 \\
\hline PC-KUS ${ }^{a}$ & 28 & 1.2 & 1.2 & 0.0 & 3.8 \\
\hline KUVA (khellin + UVA) & 6 & 1.2 & 1.4 & 0.0 & 3.0 \\
\hline UV and nutrient supplement & 60 & 1.2 & 1.1 & 0.0 & 3.7 \\
\hline UVB & 58 & 1.1 & 1.1 & 0.0 & 3.8 \\
\hline Other & 18 & 1.1 & 1.4 & 0.0 & 3.9 \\
\hline PC-KUS ${ }^{\mathrm{a}}$ and UV & 50 & 1.0 & 0.9 & 0.0 & 4.0 \\
\hline $\begin{array}{l}\text { UV with/without tacrolimus/ } \\
\text { pimecrolimus with/without } \\
\text { excimer laser }\end{array}$ & 23 & 1.0 & 1.1 & 0.0 & 3.9 \\
\hline UVA/B & 60 & 1.0 & 1.2 & 0.0 & 4.0 \\
\hline Homeopathic & 17 & 0.9 & 0.9 & 0.0 & 2.8 \\
\hline Nutrient supplement & 23 & 0.8 & 1.1 & 0.0 & 3.7 \\
\hline Vitamin $\mathrm{D}_{3}$ & 3 & 0.8 & 1.1 & 0.0 & 1.6 \\
\hline Excimer laser & 17 & 0.8 & 1.1 & 0.0 & 3.8 \\
\hline Tacrolimus & 39 & 0.7 & 1.1 & 0.0 & 3.9 \\
\hline Self-tanner & 19 & 0.7 & 0.6 & 0.0 & 2.5 \\
\hline PUVA/B & 44 & 0.7 & 1.1 & 0.0 & 3.9 \\
\hline Vitix ${ }^{b}$ & 10 & 0.6 & 0.8 & 0.0 & 2.4 \\
\hline Pimecrolimus & 12 & 0.6 & 1.1 & 0.0 & 3.5 \\
\hline Ginkgo biloba & 13 & 0.5 & 0.5 & 0.0 & 1.6 \\
\hline Light protection & 5 & 0.5 & 0.6 & 0.0 & 1.6 \\
\hline Cortisone & 7 & 0.3 & 0.6 & 0.0 & 1.4 \\
\hline$\beta$-Carotene & 8 & 0.2 & 0.3 & 0.0 & 0.8 \\
\hline UVA/B without specification & 12 & 0.1 & 0.3 & 0.0 & 1.0 \\
\hline Transplantation & 2 & 0.0 & 0.0 & 0.0 & 0.0 \\
\hline
\end{tabular}

${ }^{\mathrm{a}}$ Pseudocatalase cream. ${ }^{\mathrm{b}}$ Gel containing herbal extracts with catalase and superoxide dismutase.

The data on therapy show that most patients with vitiligo have already experienced a broad spectrum of treatments. Yet only a few therapies are considered to be beneficial from the patients' perspective. Surprisingly, Dead Sea treatment is among the options most valued by the patients, followed by cosmetic measures such as camouflage and self-tanners. By contrast, treatment options frequently prescribed by dermatologists such as topical steroids and vitamin $\mathrm{D}$ analogues were rated mostly negatively. 
In order to achieve more reliable results of patientderived benefit assessments, the PBI was used. Instead of single-item ratings, the PBI reflects the global benefit of a defined therapy based on a composite index [23]. Based on the PBI ratings on the last treatment performed, a pattern of therapeutic benefits was detected. The global PBI over all treatments was 1.03 compared to a PBI of $2.5 \pm$ 1.1 in patients in a national survey on psoriasis [25]. This finding suggests that most of the vitiligo treatments used have no substantial therapeutic benefit. The authors point out, however, that only a few patients had already undergone those treatments recommended in the international literature (e.g. only $20 \%$ had had PUVA treatment, $19 \%$ pseudocatalase and $10 \%$ topical steroids). Many of the patients included in this study were not treated with the entire dermatological spectrum. One explanation may be that many patients have given up finding a beneficial treatment before trying all treatment options available. Another interpretation would be that the physicians, rather than the patients, are not informed or willing to prescribe the therapies in use.

Possible limitations of this study lie in the selection resulting from questioning self-help groups and - with respect to the clinical features - in questioning the patients face to face. The first point may be offset by the fact that the sample is larger than all studies published to date. Questioning patients concerning clinical features has been found to be effective by convergent testing, with body schema and with quality of life [24, 26, 27], for example. Another frequent selection bias which cannot be ruled out in this study is the fact that the data can only be obtained from those patients who are motivated to answer. Accordingly, the results do only reflect the opinions and experiences of these patients.

Further insight into the benefits of vitligo treatment may be gained from recently published methods of neuronal network models $[28,29]$.

Taken together, the data indicate a great need for beneficial therapy options in vitiligo, which are not provided by the therapies used thus far, plus continued medical education for dermatologists in prescribing appropriate treatments while also encouraging patients not to give up their search for beneficial treatment options.

\section{Acknowledgments}

This project was supported by a research grant from the 'Deutscher Vitiligo Verein' (DVV) (Vitiligo Patient Organization). We thank the 'Deutscher Vitiligo Verein e.V.' and the 'Deutscher Vitiligo Bund e.V.' for their excellent cooperation.

\section{References}

1 Hahn SK, Nordlund JJ: Vitiligo. Oxford, Blackwell Sciences, 2000, pp 1-306.

2 Masini C, Abeni D: Vitiligo; in Williams $\mathrm{H}$, Birgby M, Diepgen T, Herxheimer A, Naldi L, Rzany B (eds): Evidence-Based Dermatology, ed 4. London, BMJ Publishing Group, 2003.

3 Whitton ME, Ashcroft DM, Barrett CW, Gonzalez U: Interventions for vitiligo. Cochrane Database Syst Rev 2006;1:CD003263.

4 Spritz RA: The genetics of generalized vitiligo. Curr Dir Autoimmun 2008;10:244-257.

-5 Salzer BA, Schallreuter KU: Investigation of the personality structure in patients with vitiligo and a possible association with impaired catecholamine metabolism. Dermatology 1995;190:109-115.

6 6 Le Poole IC, Luiten RM: Autoimmune etiology of generalized vitiligo. Curr Dir Autoimmun 2008;10:227-243.

7 Schallreuter KU, Bahadoran P, Picardo M, et al: Vitiligo pathogenesis: autoimmune disease, genetic defect, excessive reactive oxygen species, calcium imbalance, or what else? Exp Dermatol 2008;17:139-140.
8 Namazi MR: Neurogenic dysregulation, oxidative stress, autoimmunity, and melanocytorrhagy in vitiligo: can they be interconnected? Pigment Cell Res 2007;20:360-363.

9 Mosher DB, Fitzpatrick TB, Ortonne JP, Hori Y: Disorders of pigmentation; in Fitzpatrick T, Eisen A, Wolff K, Freedberg I, Austen K (eds): Fitzpatrick's Dermatology in General Medicine, ed 4. New York, McGraw-Hill, 1993.

10 Picardi A, Abeni D: Stressful life events and skin diseases: disentangling evidence from myth. Psychother Psychosom 2001;70:118136.

11 Sukan M, Maner F: The problems in sexual functions of vitiligo and chronic urticaria patients. J Sex Marital Ther 2007;33:55-64.

12 Porter JR, Beuf AH: Racial variation in reaction to physical stigma: a study of degree of disturbance by vitiligo among black and white patients. J Health Soc Behav 1991;32. 192-204.

13 Porter JR, Beuf AH, Lerner A, Nordlund J: Personal response of patients to vitiligo. The importance of the interaction. Arch Dermatol 1978;114:1384-1385.
14 Rumpf HJ, Löntz W, Uesseler S: A self-administered version of a brief measure of suffering: first aspects of validity. Psychother Psychosom 2004;73:53-56

15 Ongenae K, Van Geel N, De Schepper S, Naeyaert JM: Effect of vitiligo on self-reported health-related quality of life. Br J Dermatol 2005; 152:1165-1172.

-16 Schmid-Ott G, Künsebeck HW, Jecht E, Shimshoni R, Lazaroff T, Schallmayer S, Calliess IT, Malewski P, Lamprecht F, Götz A: Stigmatization experience, coping and sense of coherence in vitiligo patients. J Eur Acad Dermatol Venereol 2007;21:456-461.

17 Whitton ME, Ashcroft DM, González U: Therapeutic interventions for vitiligo. J Am Acad Dermatol 2008;59:713-717.

18 Gawkrodger DJ, Ormerod AD, Shaw L, Mauri-Sole I, Whitton ME, Watts MJ, Anstey AV, Ingham J, Young K: Guideline for the diagnosis and management of vitiligo. Br J Dermatol 2008;159:1051-1076.

19 Fenton JS, Bergstrom KG: Vitiligo: nonsurgical treatment options and the evidence behind their use. J Drugs Dermatol 2008;7: 705-711. 
20 Njoo MD, Westerhof W, Bos JD, Bossuyt PM: The development of guidelines for the treatment of vitiligo. Clinical Epidemiology Unit of the Istituto Dermopatico dell'Immacolata-Istituto di Recovero e Cura a Carattere Scientifico (IDI-IRCCS) and the Archives of Dermatology. Arch Dermatol 1999;135:1514-1521.

21 Rychlik R, Wertheimer A, Rusche H, Augustin $\mathrm{M}$, Nelles S, Böcking W: Policy decision making and outcomes research in drug utilization. Z Gesundheitswiss/J Public Health 2005;1:1-14.
22 Zentner A, Velasco-Garrido M, Busse R: Methods for the comparative evaluation of pharmaceuticals. GMS Health Technol Assess 1. 2005. http://www.egms.de/en/journals/hta/2005-1/hta000009.shtml (accessed May 29, 2007).

23 Augustin M, Gajur AI, Reich C, Rustenbach SJ, Schaefer I: Benefit evaluation in vitiligo treatment: development and validation of a patient-defined outcome questionnaire. Dermatology 2008;217:101-106.

24 Stangier U, Ehlers A, Gieler U: Fragebogen zur Bewältigung von Hautkrankheiten (FBH). Handanweisung. Göttingen, Hogrefe, 1996.

25 Augustin M, Reich K, Reich C, Purwins S Rustenbach SJ, Schaefer I, Radtke M: Quality of psoriasis care in Germany - Results of the national study PsoHealth 2007. J Dtsch Dermatol Ges 2008;8:640-645.
26 Rumpf HJ, Löntz W, Uesseler S: A self-administered version of a brief measure of suffering: first aspects of validity. Psychother Psychosom 2004;73:53-56.

27 Fleischer AB Jr, Feldman SR, Dekle CL: The SAPASI is valid and responsive to psoriasis disease severity changes in a multi-center clinical trial. J Dermatol 1999;26:210-215.

28 Cazzaniga S, Sassi F, Mercuri SR, Naldi L: Prediction of clinical response to excimer laser treatment in vitiligo by using neural network models. Dermatology 2009;219:133137.

29 Renders JM, Simonart T: Role of artificial neural networks in dermatology. Dermatology 2009;219:102-104. 